\title{
A Novel Approach to Flurbiprofen Pulsatile Colonic Release: Formulation and Pharmacokinetics of Double-Compression-Coated Mini-Tablets
}

\author{
Sateesh Kumar Vemula ${ }^{1,2,3,4}$
}

Received 11 March 2015; accepted 18 May 2015; published online 28 May 2015

\begin{abstract}
A significant plan is executed in the present study to study the effect of double-compression coating on flurbiprofen core mini-tablets to achieve the pulsatile colonic delivery to deliver the drug at a specific time as per the patho-physiological need of the disease that results in improved therapeutic efficacy. In this study, pulsatile double-compression-coated tablets were prepared based on timecontrolled hydroxypropyl methylcellulose $\mathrm{K} 100 \mathrm{M}$ inner compression coat and $\mathrm{pH}$-sensitive Eudragit S100 outer compression coat. Then, the tablets were evaluated for both physical evaluation and drugrelease studies, and to prove these results, in vivo pharmacokinetic studies in human volunteers were conducted. From the in vitro drug-release studies, F6 tablets were considered as the best formulation, which retarded the drug release in the stomach and small intestine $(3.42 \pm 0.12 \%$ in $5 \mathrm{~h})$ and progressively released to the colon $(99.78 \pm 0.74 \%$ in $24 \mathrm{~h})$. The release process followed zero-order release kinetics, and from the stability studies, similarity factor between dissolution data before and after storage was found to be 88.86 . From the pharmacokinetic evaluation, core mini-tablets producing peak plasma concentration $\left(C_{\max }\right)$ was $14,677.51 \pm 12.16 \mathrm{ng} / \mathrm{ml}$ at $3 \mathrm{~h} T_{\max }$ and pulsatile colonic tablets showed $C_{\max }=12,374.67 \pm$ $16.72 \mathrm{ng} / \mathrm{ml}$ at $12 \mathrm{~h} T_{\max }$. The area under the curve for the mini and pulsatile tablets was $41,238.52$ and $72,369.24 \mathrm{ng}-\mathrm{h} / \mathrm{ml}$, and the mean resident time was 3.43 and $10.61 \mathrm{~h}$, respectively. In conclusion, development of double-compression-coated tablets is a promising way to achieve the pulsatile colonic release of flurbiprofen.
\end{abstract}

KEY WORDS: core mini-tablets; double-compression coating; inner compression coat; outer compression coat; similarity factor.

\section{INTRODUCTION}

Flurbiprofen (FLB) is a drug that belongs to the class of non-steroidal anti-inflammatory drugs (NSAIDs), one of the alternative drugs for oral colonic delivery not only to treat site-specific colonic inflammation but also to give chronotherapy in rheumatoid arthritis $(1,2)$. The frequent intake of NSAI Ds like FLB leads to gastric ulceration, bleeding, and other gastric complications (3). Rheumatoid arthritis is a chronic inflammatory syndrome that has early morning symptoms such as joint pain and functional disability. To alleviate these problems, colon-specific drug delivery is the best option to accommodate both chronotherapy as well as site-specific drug release. Pulsatile drug delivery is required especially for the treatment of some common diseases, such as bronchial asth-

\footnotetext{
${ }^{1}$ Department of Pharmacy, College of Medical and Health Sciences, Wollega University, Post Box No: 395Nekemte, Ethiopia.

${ }^{2}$ Department of Pharmaceutics, Chaitanya College of Pharmaceutical Sciences, Hanamkonda, Warangal, Telangana 506001, India.

${ }^{3}$ Department of Pharmaceutics, Jangaon Institute of Pharmaceutical Sciences, Yeshwanthapur, Jangaon, Warangal, Telangana 506167, India.

${ }^{4}$ To whom correspondence should be addressed. (e-mail: vemulasatish15@gmail.com)
}

ma, hypertension, angina pectoris, allergic rhinitis, and rheumatoid arthritis with mainly night or early morning symptoms (4). Thus, the significant plan of the present study is to formulate new FLB pulsatile colon-specific double-compressioncoated mini-tablets utilizing the combination of both timecontrolled and $\mathrm{pH}$-sensitive approaches.

In general, colon-specific drug delivery can be accomplished either by film coating or compression coating processes. Among these, compression coating is the solvent-free process which is safe and inexpensive that does not require special coating equipment. The other advantage of compression coating is higher stability when compared to film coating, but it suffers from disadvantages like requirement of highly skilled persons and more care during compression to avoid compression-related problems (5). Instead of the usage of single approach, combination of both time-controlled and $\mathrm{pH}$-sensitive approaches has shown greater flexibility in the design and formulation of colon-specific drug delivery. Combining both methods can result in the optimum formulation which shows negligible drug release in the initial lag period but releases the drug completely in the colon (6). There have also been reports where the investigators have combined two or more approaches to achieve desired release profile from the tablets. Flurbiprofen pulsatile compressioncoated tablets (6), diclofenac sodium compression-coated 
tablets (7), time-controlled delivery of insulin (8), meloxicam microsponges (9), and indomethacin matrix tablets (10) are some of the recent colonic systems reported in literature. Some of the recently reported research examples on compression-coated tablets are 5-fluorouracil-hydroxypropyl methylcellulose (11), flurbiprofen-sodium alginate (12), ketorolac tromethamine-sodium alginate (13), ketorolac tromethamine-hydroxypropyl methyl cellulose (14), flurbiprofen-guar gum (15), etc. However, little published information is available on double-compression-coated tablets based on combination of time-controlled and $\mathrm{pH}$-sensitive approaches. So, it has been challenging to develop the pulsatile colon-specific double-compression-coated tablets using both time- and $\mathrm{pH}$-dependent approaches.

Mini-tablets are very small tablets compared to normal tablets offering an excellent substrate for coating with different polymeric systems. Mini-tablet technology combines the advantages of multiparticulate dosage forms with established manufacturing techniques used in tabletting (16). Additional advantages of mini-tablets include excellent size uniformity, regular shape, and a smooth surface, thereby offering an excellent substrate for coating with different polymeric systems. By considering the benefits like small size, uniform shape, and smooth surface, mini-tablets are selected as the core tablets for double-compression coating to give medium size to the final tablets along with uniform coating. In this proposal, FLB core mini-tablets were compression coated with hydroxypropyl methylcellulose K100M (HPMC) as time-controlled inner layer and Eudragit S100 (ED) as pHsensitive outer layer to achieve the pulsatile colonic delivery of FLB.

\section{MATERIAL AND METHODS}

\section{Materials}

Flurbiprofen was a gift sample from FDC Limited, Mumbai, India. HPMC K100M and Eudragit S100 were gift samples from Matrix laboratories, Hyderabad, India. All other chemicals used were of analytical grade.

\section{Preparation of Core Mini-Tablets}

FLB core mini-tablets were prepared by wet granulation method using Avicel PH 102 as a diluent. Precisely measured quantity of FLB and excipients other than glidant and lubricant passed through a 60-mesh sieve and mixed in a poly sack for 5-10 min. Then, the blend was granulated with $10 \%$ starch paste, granules were dried, sifted, and finally lubricated with talc and magnesium stearate and compressed into tablets. Each mini-tablet contains $20 \mathrm{mg}$ drug and final weight was adjusted to $60 \mathrm{mg}$. The mini-tablets were prepared with $4 \mathrm{~mm}$ round flat punches using eight station rotary tabletting machines at low speed (10 rpm). Formulation and characterization of core mini-tablets were shown in Table I.

\section{Preparation of Compression-Coated Tablets}

The prepared core mini-tablets were subjected to compression coating using various compositions given in Table II. The core tablets were coated with two distinctive layers;
HPMC K100M as time-controlled inner layer (60 mg weight) and Eudragit S100 as pH-sensitive outer layer (60 mg weight). Here, compression coating of cores is done using $6 \mathrm{~mm}$ (inner compression coat) and $8 \mathrm{~mm}$ (outer compression coat) circular flat punches by placing half of the coating material in die cavity, then cautious placing of cores in middle and finally placing the remaining half of coating material.

\section{Evaluation of Pulsatile Tablets}

The prepared double-layered compression tablets were evaluated for weight variation, hardness, friability, and drug content uniformity. For estimating weight variation, 20 tablets of each formulation were weighed using an electronic weighing balance (AW 120, Shimadzu Corporation, Japan). Measuring of hardness and friability expresses the integrity and mechanical strength of tablets. The hardness of six tablets was measured using Monsanto tablet hardness tester. Friability was determined on six tablets in a Roche friabilator (Electro lab, Mumbai, India) at $25 \mathrm{rpm}$ for $4 \mathrm{~min}$ (100 revolutions). For estimation of drug content, randomly selected 20 tablets were crushed, and the aliquot of powder equivalent to $20 \mathrm{mg}$ of drug was dissolved in suitable quantity of $\mathrm{pH} 7.4$ phosphate buffer solution. Solution was filtered and diluted and drug content determined by using HPLC method and determined at $254 \mathrm{~nm}$ using a UV detector $(6,15)$.

\section{In vitro Drug-Release Study}

To estimate the FLB amount from the compressioncoated pulsatile tablets, drug-release studies were planned using USP XXIV Type I dissolution apparatus (Electro lab, TDT-08L) at $50 \mathrm{rpm}$ speed and at $37 \pm 0.5^{\circ} \mathrm{C}$ temperature. To assist and imitate the gastrointestinal environment, different $\mathrm{pH}$ dissolution media were used in this study. At first, the drug-release studies were conducted in $0.1 \mathrm{~N} \mathrm{HCl}$ for $2 \mathrm{~h}$, then $2 \mathrm{~h}$ in $\mathrm{pH} 5.5$ buffer and followed in phosphate buffer $\mathrm{pH} 7.4$ up to $24 \mathrm{~h}$. At specific scheduled time, samples were taken $(5 \mathrm{ml})$, were collected $(n=6)$, and were restored at the same level of fresh pre-warmed media. Collected samples were filtered using $0.45-\mu \mathrm{m}$ membranes (Millipore, USA) and analyzed using HPLC method and determined at $254 \mathrm{~nm}$ using a UV detector $(6,15)$.

\section{In vitro Drug-Release Kinetics}

To illuminate the drug-release mechanism from the prepared compression-coated tablets, the data obtained from the in vitro dissolution studies was integrated to zero-order, firstorder, Higuchi, and Korsmeyer-Peppas models (17). Then, the dissolution data was also used to calculate the mean dissolution time (18) (MDT-the sum of different release fraction periods during dissolution studies divided by the initial loading dose), and $T 10 \%$ and $T 80 \%$ (time in hours to take 10 and $80 \%$ drug release, respectively) to explain the drugrelease pattern from compression-coated tablets (14).

\section{Stability Studies}

Stability studies were planned to assess the stability of FLB in compression-coated tablets with the help of the ICH 
Table I. Composition and Characterization of FLB Core Mini-Tablets

\begin{tabular}{lllll}
\hline Ingredients & Quantity $(\mathrm{mg})$ & Core tablet evaluation parameters & Number & Observed values \\
\hline Flurbiprofen & 20 & Weight variation $(\mathrm{mg})$ & 20 & $60.32 \pm 1.46$ \\
Avicel PH 102 & 35.2 & Core thickness (mm) & 20 & $1.73 \pm 0.02$ \\
Crospovidone & 3 & Core diameter $(\mathrm{mm})$ & 20 & $4.05 \pm 0.03$ \\
Starch paste $(10 \%)$ & Q.S. & Hardness $\left(\mathrm{kg} / \mathrm{cm}^{2}\right)$ & 6 & 10 \\
Talc & 1.2 & Friability $(\%)$ & 3 & 0.48 \\
Magnesium stearate & 0.6 & Content uniformity $(\%)$ & 3 & $100.12 \pm 1.24$ \\
Core weight & 60 & $\%$ drug release in 15 min $\left(\mathrm{Q}_{15}\right)$ & $99.96 \pm 0.87$ \\
\hline
\end{tabular}

Q.S. Quantity Sufficient

guidelines. Three replicates of F4 formulation tablets were sealed in apolyethylene pack with inside aluminum coating and stored at $40 \pm 2^{\circ} \mathrm{C}$ and $75 \pm 5 \% \mathrm{RH}$ in the humidity chamber for 6 months (19). Specimens were collected following 6 months of storage and determined the drug content and in vitro dissolution rate (20). Then, to prove the stability of dosage form, the similarity factor (F2) was calculated between dissolution rates of optimized tablets before and after storage. At this point, the data was statistically analyzed using paired $t$ test to test the significance of difference at the level of significance 0.05 .

\section{In vivo Pharmacokinetics-Study Design}

The study design was a two-way crossover design with a washout period of 2 weeks. Randomly selected 12 human volunteers were divided into two groups in which an immediate-release core tablets equaling to $100 \mathrm{mg}$ dose (five core mini-tablets filled in gelatin capsule) was administered to group I volunteers $(n=6)$ and colon-targeted compressioncoated tablet (five compression-coated tablets filled in gelatin capsule; $100 \mathrm{mg}$ dose) was administered to group II volunteers $(n=6)$ in the first phase of study whereas vice versa in second phase of study. Zero hour blood sample was collected from each participant as blank and received the tablets on an empty stomach along with sufficient water, and then regular food was

Table II. Composition of FLB Double-Compression-Coated Tablets

\begin{tabular}{|c|c|c|c|c|}
\hline & & $\begin{array}{l}\text { Inner } \\
\text { compression } \\
\text { coat }(60 \mathrm{mg})\end{array}$ & $\begin{array}{l}\text { Outer } \\
\text { compression } \\
\text { coat }(60 \mathrm{mg})\end{array}$ & \\
\hline $\begin{array}{l}\text { Formulation } \\
\text { code }^{\mathrm{a}}\end{array}$ & $\begin{array}{l}\text { Core } \\
\text { tablet } \\
(\mathrm{mg})\end{array}$ & $\begin{array}{l}\text { HPMC } \\
\text { K100M } \\
(\mathrm{mg})\end{array}$ & $\begin{array}{l}\text { Eudragit } \\
\text { S100 } \\
(\mathrm{mg})\end{array}$ & $\begin{array}{l}\text { Total tablet } \\
\text { weight }(\mathrm{mg})\end{array}$ \\
\hline $\mathrm{F} 1$ & 60 & 10 & - & 120 \\
\hline F2 & 60 & 20 & - & 120 \\
\hline F3 & 60 & 30 & - & 120 \\
\hline F4 & 60 & 40 & - & 120 \\
\hline F5 & 60 & 30 & 15 & 180 \\
\hline F6 & 60 & 30 & 30 & 180 \\
\hline
\end{tabular}

Tablet thickness after inner compression coating $=2.14 \pm 0.04 \mathrm{~mm}$ Tablet diameter after inner compression coating $=6.04 \pm 0.02 \mathrm{~mm}$ Tablet thickness after double-compression coating $=2.52 \pm 0.04 \mathrm{~mm}$ Tablet diameter after double-compression coating $=8.03 \pm 0.02 \mathrm{~mm}$

${ }^{a}$ Each compression coat formulation contains $1 \%$ magnesium stearate, 2\% talc, and Avicel PH 102 to make up the compression coat weight provided in normal time interims. Then, the blood samples were collected at $0.5,1,2,3,4,5,6,8,10,12,18$, and $24 \mathrm{~h}$ in pre-labeled vials in both the cases.

\section{Selection of Volunteers and Safety Assessment}

In the present study, 12 healthy volunteers $(28 \pm 2$ years, body weight $55 \pm 5 \mathrm{~kg}$ ) were included on the basis of inclusion and exclusion criteria and medical examination. The volunteers were non-smokers and were free from clinically significant disorders. Before starting the study, the nature of the study was explained and the written consent from all volunteers was taken. The Institutional Ethical Committee (Approval No. FLB/HPMC/05/IHEC/2013) approved the protocol of the in vivo study of FLB colontargeted compression-coated tablets in human volunteers. Each subject underwent a physical examination, routine clinical chemistry, and urinalysis at the beginning and at the end of the study. No adverse events were noted for any dosage form in any subject.

\section{HPLC Analysis of FLB in Human Plasma}

To estimate the FLB content present in plasma specimens, HPLC method developed by Vemula et al. $(6,15)$ was utilized as a part of the present study. The collected blood samples were centrifuged at $4000 \mathrm{rpm}$ for $15 \mathrm{~min}$, and the serum was separated and transferred to 5-ml micro centrifuge tubes. To the $1 \mathrm{ml}$ of the above serum, $1 \mathrm{ml}$ of acetonitrile was added and centrifuged for $10 \mathrm{~min}$ at $3000 \mathrm{rpm}$, and the supernatant liquid was separated and stored at $-40^{\circ} \mathrm{C}$ until the analysis of sample for unchanged drug. Then, the quantitative determination of FLB in human plasma was determined at $254 \mathrm{~nm}$ using a UV detector using HPLC method.

\section{Pharmacokinetic Analysis}

All the conceivable and required pharmacokinetic parameters were calculated utilizing FLB plasma concentration-time data. From the time versus plasma concentration graph, the peak plasma concentration $\left(C_{\max }\right)$ and the time to reach peak plasma levels $\left(T_{\max }\right)$ were acquired. Other pharmacokinetic parameters were computed using Kinetica software (Kineitca 2000 version 3.0, InnaPhase Corporation, 2000). The elimination rate constant (ke) was calculated from linear part in the elimination phase of a semi-log plot of concentration versus time. The area under the concentration versus time curve (AUC) from 0 to $t$ h was determined by concerning the 
Table III. Physical Properties of FLB Compression-Coated Tablets

\begin{tabular}{|c|c|c|c|c|}
\hline Formulation & $\begin{array}{l}\text { Weight } \\
\text { variation }^{\mathrm{a}} \\
(\mathrm{mg})\end{array}$ & $\begin{array}{l}\text { Hardness }^{\mathrm{b}} \\
\left(\mathrm{kg} / \mathrm{cm}^{2}\right)\end{array}$ & $\begin{array}{l}\text { Friability } \\
(\%)\end{array}$ & $\begin{array}{l}\text { Drug } \\
\text { content }^{\mathrm{c}} \\
(\%)\end{array}$ \\
\hline $\mathrm{F} 1$ & $120.42 \pm 3.02$ & $4.52 \pm 0.32$ & 0.34 & $99.92 \pm 1.18$ \\
\hline $\mathrm{F} 2$ & $119.91 \pm 2.92$ & $4.63 \pm 0.36$ & 0.38 & $100.08 \pm 1.27$ \\
\hline F3 & $121.05 \pm 3.12$ & $4.42 \pm 0.28$ & 0.42 & $100.12 \pm 1.06$ \\
\hline F4 & $120.74 \pm 2.79$ & $4.34 \pm 0.24$ & 0.39 & $99.86 \pm 1.15$ \\
\hline F5 & $180.56 \pm 2.81$ & $5.31 \pm 0.28$ & 0.28 & $100.12 \pm 1.06$ \\
\hline F6 & $180.24 \pm 2.54$ & $5.27 \pm 0.34$ & 0.28 & $100.12 \pm 1.06$ \\
\hline
\end{tabular}

${ }^{a}$ All values represent mean \pm standard deviation, $n=20$

${ }^{b}$ All values represent mean \pm standard deviation, $n=6$

${ }^{c}$ All values represent mean \pm standard deviation, $n=3$

trapezoidal rule and then the AUC extended to infinity ( 0 to $\infty \mathrm{h}$ ) that speaks to the degree of bioavailability of FLB. The area under first moment curve (AUMC) was acquired from the plot of product of plasma drug concentration and time versus time. The $\mathrm{AUMC}_{0-t}$ and $\mathrm{AUMC}_{0-\infty}$ was estimated by trapezoidal rule. The mean residence time (MRT) was determined from AUC and AUMC. Then, the assessed pharmacokinetic parameters of both immediate-release and colontargeted tablets of FLB were subjected to statistical analysis using analysis of variance (ANOVA) to test the significance of difference. A value of $P<0.05$ was considered statistically significant.

\section{In vitro-In vivo Correlation (IVIVC)}

In this study, the in vitro cumulative percent of FLB release of optimized formulation was compared against the extent of absorption, i.e., cumulative AUC values of the same formulation.

\section{RESULTS}

\section{Evaluation of FLB Double-Compression-Coated Tablets}

In weight variation test, the average weight of prepared tablets was given in Table III. The hardness and friability of tablets were found to be $4-5 \mathrm{~kg} / \mathrm{cm}^{2}$ and below $0.5 \%$, respectively, signifying the integrity and strength of tablets. The prepared tablets were found to be uniform in the drug content and contain in the range of $99.86 \pm 1.15 \%$ to $100.12 \pm 1.06 \%$. In a word, all the tablets showed acceptable results in the sense of physical characteristics along with good mechanical integrity. Table III showed all the physical parameters evaluated for double-compressioncoated tablets.

\section{In vitro Drug-Release Studies}

Before going to compression coating, preliminary studies (not shown in the manuscript) conducted for the selection of suitable polymer for inner and external compression coat to achieve the pulsatile colonic drug release different formulations prepared and evaluated for drug release. Among the different viscosity grades of HPMC, ethyl cellulose, sodium alginate, and hydroxypropyl cellulose, HPMC K100M was selected as inner compression coat polymer based on the results of swelling index and drug-release studies. Based on the $\mathrm{pH}$ sensitivity and lag time to dissolve the enteric compression coat, Eudragit S100 was selected as outer compression coat polymer when compared to Eudragit L100, cellulose acetate phthalate, and polyvinyl pyrrolidone acetate phthalate.

Figure 1 explains the effect of compression coating on the release of FLB from double-compression-coated tablets (F1F6). Formulations F1-F4 demonstrated the effect of inner

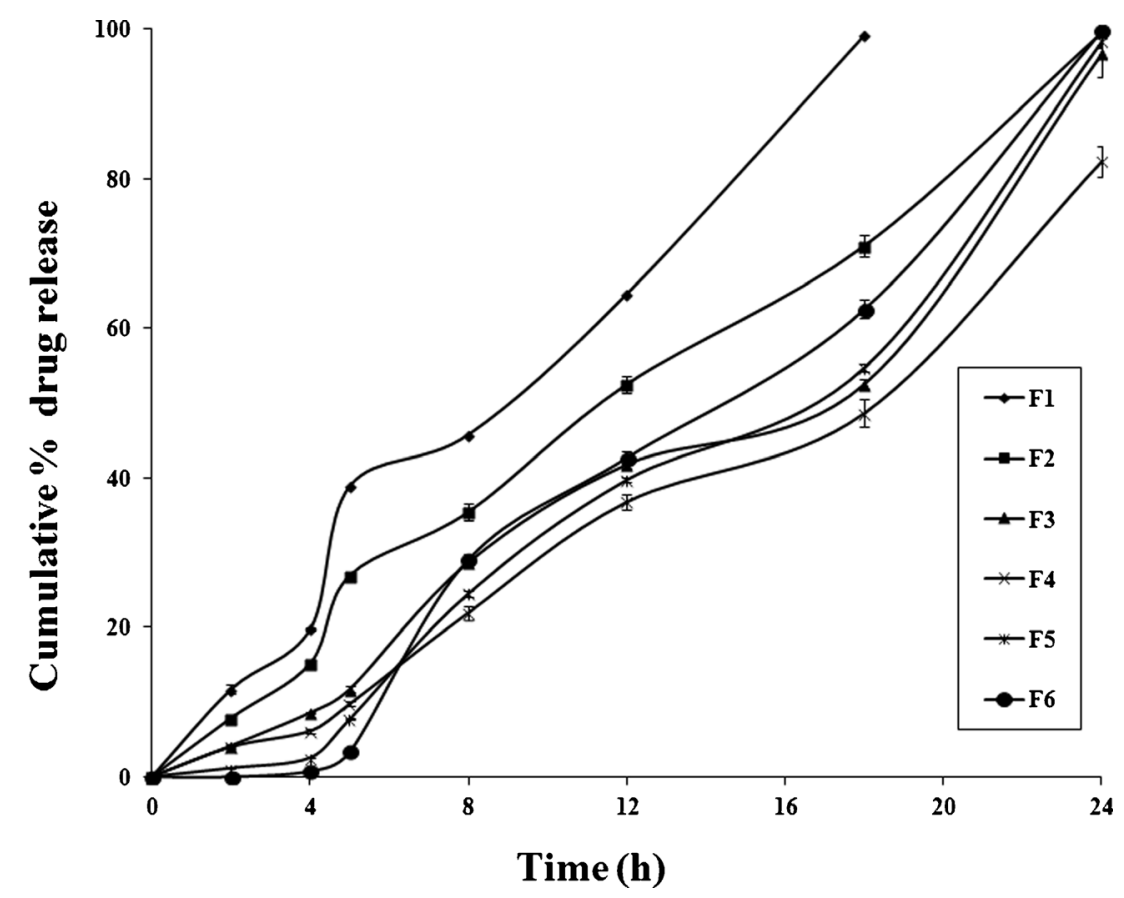

Fig. 1. Release profile of FLB from compression-coated tablets $(n=6)$ 


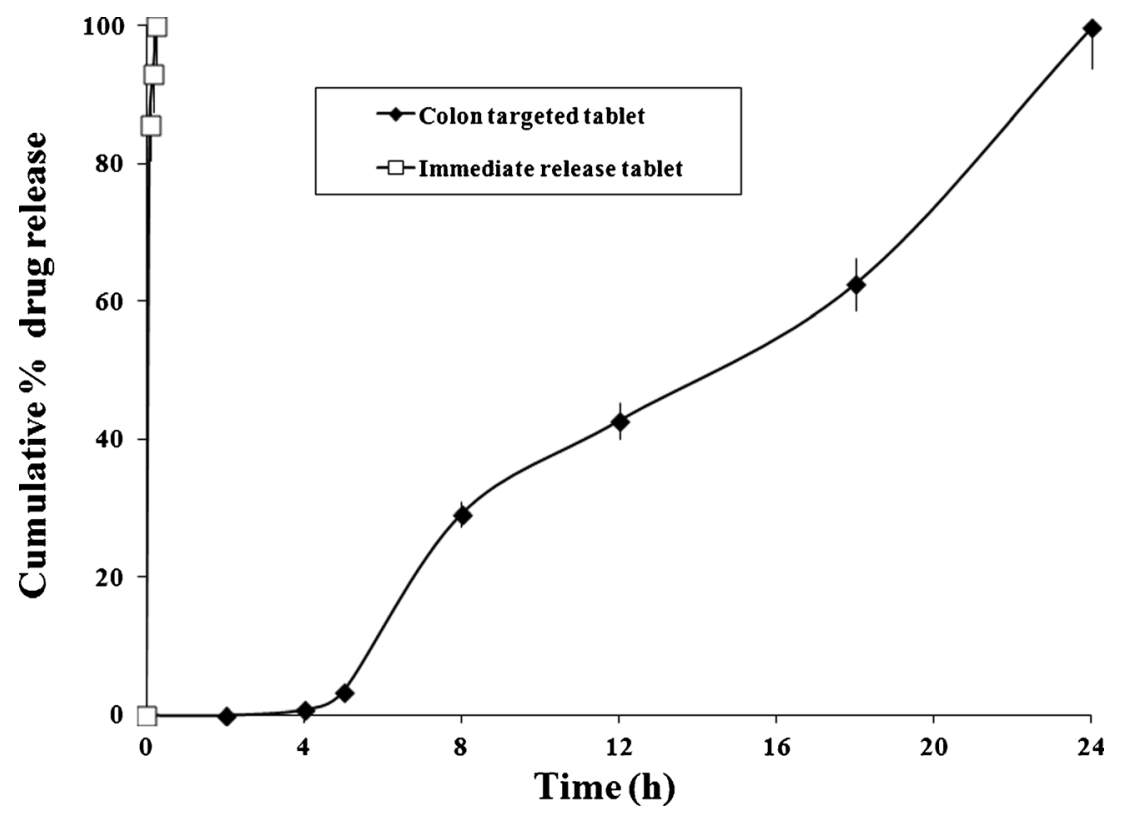

Fig. 2. Release profile of FLB from colon-specific double-compression-coated tablets F6 and core mini-tablets $(n=6)$

compression coat, i.e., HPMC K100M on FLB release from the core mini-tablets. From above formulations, F3 tablets showed $11.78 \pm 0.35 \%$ drug release within $5 \mathrm{~h}$ but it was gradually increased after $5 \mathrm{~h}$ and found to be $96.78 \pm 0.59 \%$ in $24 \mathrm{~h}$. From this study, incorporation of $30 \mathrm{mg}$ of HPMC K100M in the total tablet weight showed satisfactory data and used to monitor the influence of outer compression coat of Eudragit S100. The effect of the Eudragit S100 incorporation as outer coating is mainly to decrease the drug release in lag period i.e., in first $5 \mathrm{~h}$ and the cumulative mean percent of FLB released from F6 formulation (30 mg of Eudragit S100) was found to $3.42 \pm 0.12 \%$ in $5 \mathrm{~h}$ of testing, and after $5 \mathrm{~h}$ lag time, the percent drug release was increased gradually to $99.78 \pm 0.74 \%$ in 24 h. And finally, Fig. 2 explains the considerable difference in the drug-release pattern from FLB core mini-tablets and compression-coated tablets.

\section{In vitro Drug-Release Kinetics}

The drug-release mechanism and kinetics of FLB is determined by the application of Korsmeyer-Peppas model, Higuchi's model, and zero-order and first-order kinetics to dissolution data. The tablet formulations (F3 and F6) follow the zero-order release as their $r^{2}$ values are found to be 0.9924 and 0.9958. The drug-release mechanism followed nonFickian diffusion (super case-II), since they fitted well with Korsmeyer-Peppas models as their $r^{2}$ values in the range of 0.9921 and 0.9933 with $n$ value above 1 . This indicates that drug release depends on swelling, relaxation, and erosion of polymer with zero-order release kinetics. The MDT values of F3 and F6 tablets were found to be 14.08 and 13.99, respectively. $T 10 \%$ and $T 80 \%$ values of best formulation F6 was found to be 6.8 and $19.7 \mathrm{~h}$, respectively. All these findings were given in Table IV.

\section{Stability Studies}

In the stability studies, after storage of 6 months, the formulation was subjected to a drug assay and in vitro dissolution studies, and the results were shown in Table V. From the statistical analysis, there was no significant difference between before and after storage $(P<0.05)$. The similarity index value between dissolution profiles of optimized formulation before and after storage was found to be 88 .

\section{Pharmacokinetics in Healthy Volunteers}

In the present study, various possible pharmacokinetic parameters were determined for double-compression-coated colon-specific tablet F6 in comparison to immediate-release core mini-tablets. The in vivo data (FLB plasma concentrations) comparison between immediate- and colon-release tablets were given in Fig. 3. The mean pharmacokinetic parameters calculated were given in Table VI.

Table IV. Drug-Release Kinetics Parameters of Selected Compression-Coated Tablets

\begin{tabular}{lcclccccc}
\hline Formulation code & $\begin{array}{l}\text { Zero order } \\
\left(R^{2}\right)\end{array}$ & $\begin{array}{l}\text { First order } \\
\left(R^{2}\right)\end{array}$ & $\begin{array}{l}\text { Higuchi } \\
\left(R^{2}\right)\end{array}$ & $\begin{array}{l}\text { Korsmeyer-Peppas } \\
\left(R^{2}\right)\end{array}$ & $\begin{array}{l}\text { Peppas } \\
(n)\end{array}$ & $\begin{array}{l}\text { MDT } \\
(\mathrm{h})\end{array}$ & $\begin{array}{l}T 10 \% \\
(\mathrm{~h})\end{array}$ & $\begin{array}{l}T 80 \% \\
(\mathrm{~h})\end{array}$ \\
\hline F3 & 0.9924 & 0.8251 & 0.9346 & 0.9921 & 1.2282 & 14.08 & 4.5 \\
F6 & 0.9958 & 0.8432 & 0.9372 & 0.9933 & 1.2396 & 13.99 & 6.8 & 19.7 \\
\hline
\end{tabular}

$R^{2}$ correlation coefficient, $M D T$ mean dissolution time, $T 10 \%$ time to release $10 \%$ drug release, $T 80 \%$ time to release $80 \%$ drug release 
Table V. Stability Studies of FLB Compression-Coated Tablets F6

\begin{tabular}{lrrlc}
\hline Time (h) & \multicolumn{1}{l}{$\begin{array}{l}\text { Before } \\
\text { storage }\end{array}$} & \multicolumn{1}{l}{$\begin{array}{l}\text { After 6 } \\
\text { months }\end{array}$} & $\begin{array}{l}t \text { test } \\
\text { at 0.05 LS }\end{array}$ & $\begin{array}{l}\text { Similarity } \\
\text { factor (F2) }\end{array}$ \\
\hline 0 & $0.00 \pm 0.00$ & $0.00 \pm 0.00$ & Not significant & 88.86 \\
2 & $0.00 \pm 0.00$ & $0.00 \pm 0.00$ & & \\
4 & $0.78 \pm 0.08$ & $0.76 \pm 0.04$ & & \\
5 & $3.42 \pm 0.12$ & $3.16 \pm 0.16$ & & \\
8 & $29.18 \pm 0.78$ & $27.86 \pm 0.56$ & & \\
12 & $42.72 \pm 0.65$ & $41.42 \pm 0.58$ & & - \\
18 & $62.56 \pm 0.94$ & $60.97 \pm 0.62$ & & \\
24 & $99.78 \pm 0.74$ & $98.72 \pm 0.94$ & & \\
$\%$ Assay & $100.12 \pm 1.06$ & $99.81 \pm 1.26$ & Not significant & - \\
\hline
\end{tabular}

\section{In vitro-In vivo Correlation (IVIVC)}

IVIVC was carried out for F6 tablets by plotting the in vitro cumulative percent of FLB release on $X$-axis and the cumulative AUC obtained after oral administration on $Y$-axis (Fig. 4). From the above plot, it was observed that the correlation coefficient value, i.e., $r^{2}=0.9079$ signifying good correlation between the in vitro cumulative percent drug release and in vivo drug absorbed (AUC).

\section{DISCUSSION}

In the formulation and development of tablet dosage forms, the big challenge to the formulation scientists is to prepare a tablet with acceptable physical properties and mechanical strength that could not adversely affect the drugrelease pattern. After the compression of tablets, The tablets were evaluated for various physical properties like weight variation, thickness, hardness, and friability to prove the compliance with pharmacopoeial standards. In weight variation test, the average percentage deviation of all tablet formulations was found to be within the pharmacopoeial limits. All the prepared tablet formulations were found uniform in hardness, friability, and drug content. Determination of hardness and friability indicates the tablet strength and mechanical integrity.

From the preliminary studies to optimize the suitable polymer for compression coating, different formulations were prepared and evaluated for drug release, and from the dissolution studies, HPMC K100M and Eudragit S100 were selected as the inner and outer compression coat polymers, respectively. The swelling index of HPMC K100M showed higher value than other polymers. Among the HPMC, ethyl cellulose, sodium alginate, and hydroxypropyl cellulose as inner compression coat, HPMC was superior not only in drug retardation but also in swelling, compressibility, and mechanical integrity, and among the different HPMC viscosity grades, HPMC K100M was superior in the above parameters. Formulations with HPMC of high viscosity formed swollen gel compression coated with substantial integrity, and the drug release was in a controlled manner which could be due to the better control of water and drug diffusion. Similar type or results were observed with ketorolac tromethamine colontargeted compression-coated tablets developed by Vemula et al. (14). Hence, HPMC K100M was considered as the suitable polymer for inner compression coating. Among the

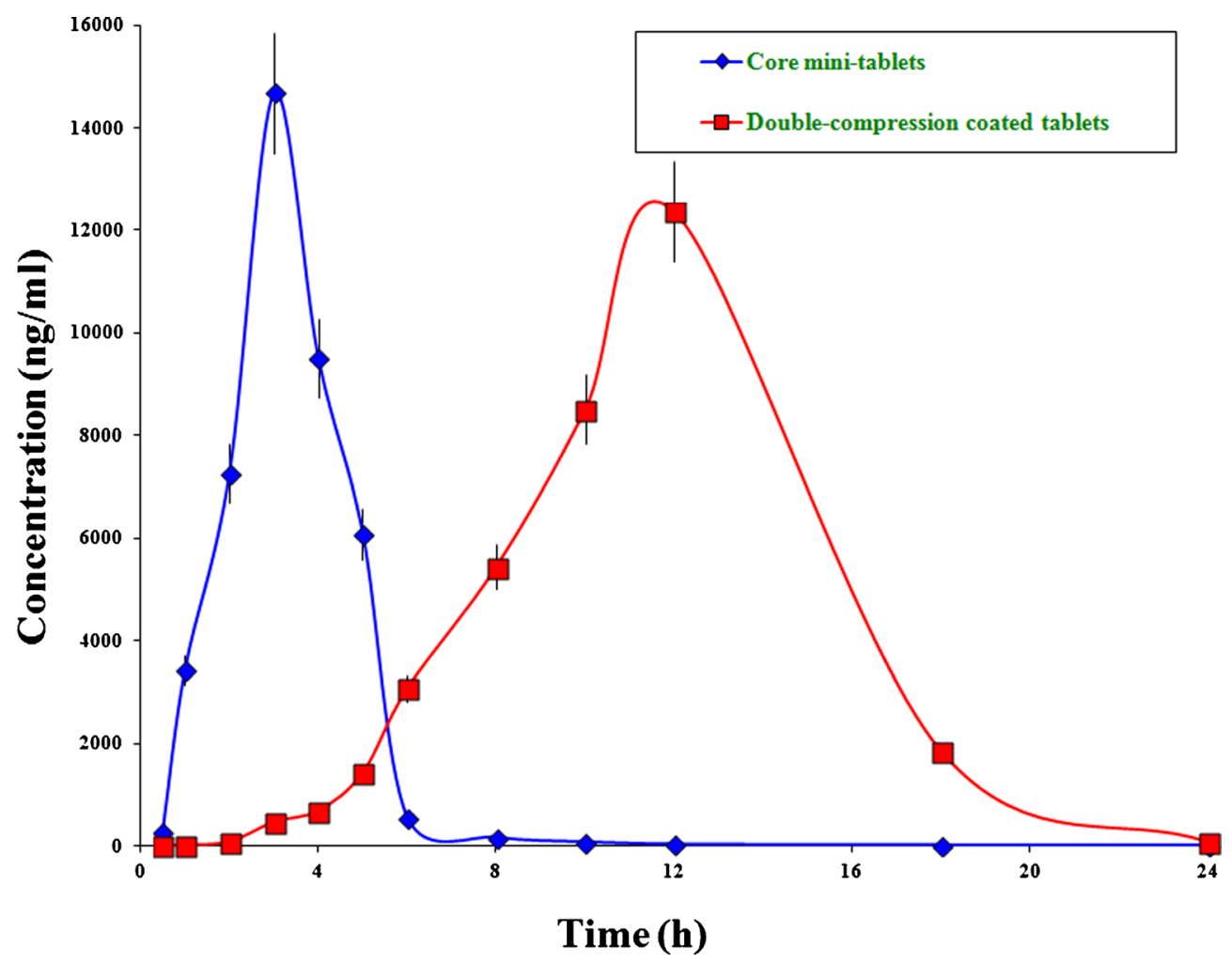

Fig. 3. Time versus mean plasma concentration profiles of FLB following the oral administration of colonspecific double-compression-coated tablets F6 and immediate-release core mini-tablets in human volunteers $(n=12)$ 
Table VI. Pharmacokinetics of FLB Compression-Coated and Core Mini-Tablets

\begin{tabular}{llll}
\hline & $\begin{array}{l}\text { FLB compression- } \\
\text { coated tablets }\end{array}$ & $\begin{array}{l}\text { FLB core mini- } \\
\text { tablets }\end{array}$ & $P$ \\
\hline C max $(\mathrm{ng} / \mathrm{ml})$ & $12,374.67 \pm 16.72$ & $14,677.51 \pm 12.16$ & $<0.05$ \\
T max $(\mathrm{h})$ & $12.00 \pm 0.01$ & $3.00 \pm 0.01$ & $<0.05$ \\
AUC $_{0-\infty}(\mathrm{ng}-\mathrm{h} / \mathrm{ml})$ & $72,369.24 \pm 153.26$ & $41,238.52 \pm 96.11$ & $<0.05$ \\
AUMC $_{0-\infty}(\mathrm{ng}-\mathrm{h} / \mathrm{ml})$ & $768,172.42 \pm 2102.06$ & $141,364.81 \pm 1431.09$ & $<0.05$ \\
MRT (h) & $10.61 \pm 0.02$ & $3.43 \pm 0.03$ & $<0.05$ \\
\hline
\end{tabular}

various enteric polymers used, Eudragit S 100 was superior in the sense of protection from acidic $\mathrm{pH}$ and to obtain the required lag time; hence, it was selected as the outer compression coating polymer.

From the in vitro dissolution studies, formulation containing $30 \mathrm{mg}$ of HPMC K100M in inner compression coat and $30 \mathrm{mg}$ of Eudragit S100 in outer compression coat were able to provide the pulsatile colon-specific FLB release and succeeded to not only retard the drug release in stomach and small intestine but also release the drug in large amounts at a desired colon site. In comparison to drug-release profiles of F4 and F6 formulations, F6 formulation showed low amount of drug release in the first $5 \mathrm{~h}$ and increased amount of drug release in the colon than $\mathrm{F} 4$ formulation due to the presence of Eudragit outer compression coat. This was explained due to the presence of Eudragit S100 outer coating that retarded the initial swelling of the HPMC inner coat in acidic to weakly acidic $\mathrm{pH}$, but in alkaline $\mathrm{pH}$, enhancement in drug release rate was observed due to the dissolution of Eudragit S100 from the coat with time, resulting in a porous coat structure that resulted in a faster drug release in the colon. A similar type of results was observed in a study developed by Veerareddy et al., i.e., flurbiprofen compression-coated tablets (6). But when compared to the above study, the present study achieved the better results in low concentration of polymer due to the advantage of high viscosity grade of HPMC and double-compression coating. So, F6 formulation based on combination of both time-controlled and $\mathrm{pH}$-sensitive approaches was a successful formulation to achieve the pulsatile colonic release of FLB, and further, this formulation was selected for in vivo pharmacokinetic studies to prove it.

The drug-release kinetics studies revealed high correlation coefficient values for zero order. Zero-order release was also observed in a study with 5-fluorouracil using HPMC in the compression coat (21). The high regression value of Higuchi model proved that the drug release followed diffusion mechanism and the $n$ values indicated a super case-II transport. The MDT was increased as the concentration of HPMC K100M was increased. Time in hours to take 10 and $80 \%$ drug release $(T 10 \%$ and $T 80 \%$, respectively) explained the ability to attain the pulsatile drug release to give sufficient lag time and site-specific release. After storage of 6 months, the formulation was subjected to a drug assay and in vitro dissolution studies and the data showed that there was no significant change in formulation in the sense of drug content and dissolution behavior. The similarity index value was found as 88.86 , which is more than 50 indicating similarity between the dissolution profile before and after storage.

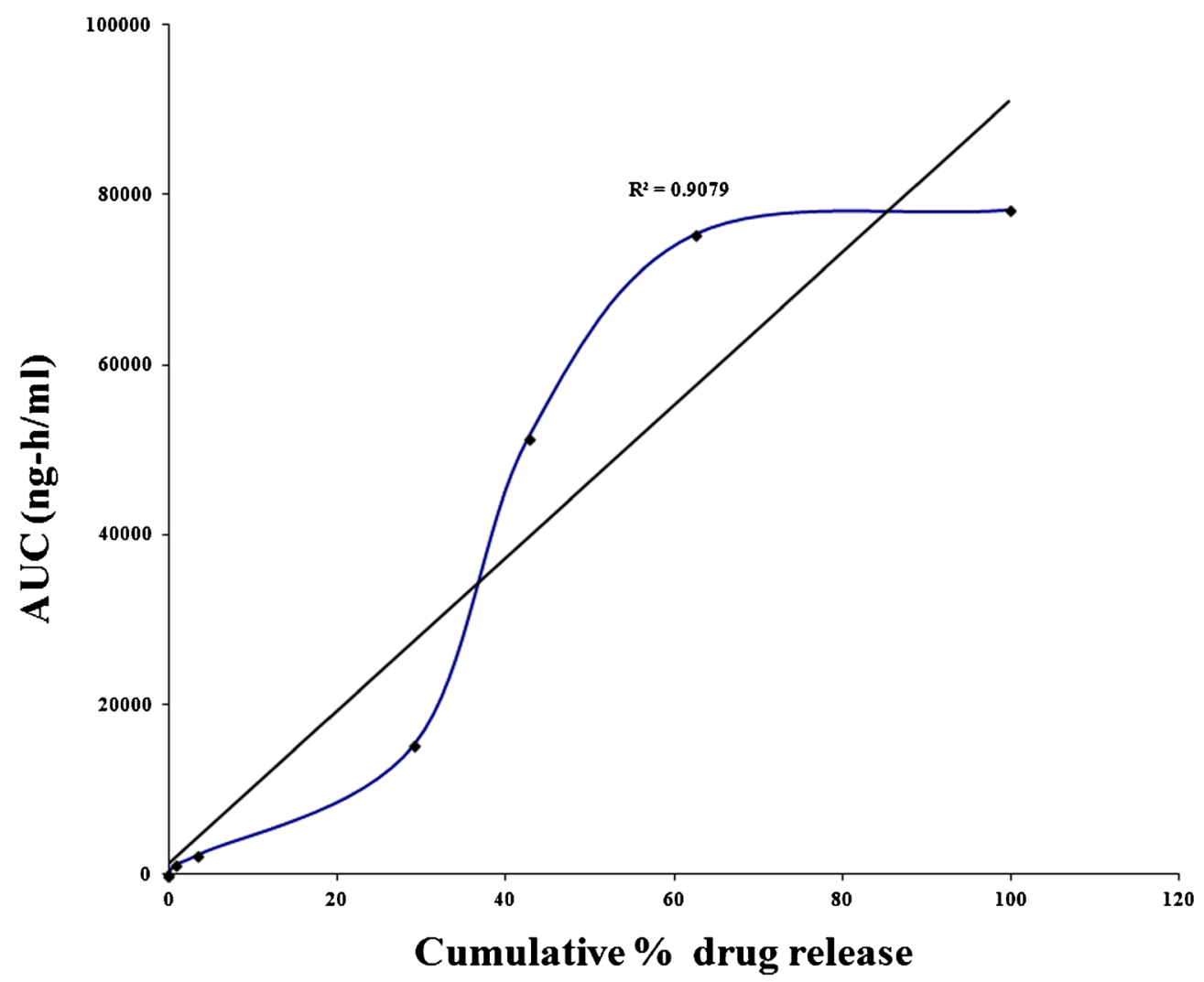

Fig. 4. In vitro-in vivo correlation plot of colon-specific double-compression-coated tablets F6 
From the pharmacokinetic evaluation, FLB appeared in plasma at a significant level within $30 \mathrm{~min}$ after oral administration of core mini-tablets whereas double-compressioncoated tablets took about $5 \mathrm{~h}$. Core mini-tablets disintegrated quickly in gastrointestinal tract (GIT) that indicates rapid absorption of the drug from upper GIT to give $C_{\max }$ of $14,677.51 \pm 12.16 \mathrm{ng} / \mathrm{ml}$ at $3 \mathrm{~h} T_{\max }$. On oral administration of F6 tablets, FLB reached peak concentration $\left(C_{\max }=12,374.67\right.$ $\pm 16.72 \mathrm{ng} / \mathrm{ml}$ ) at $12 \mathrm{~h} T_{\max }$, which revealed that the compression coating was able to retard the drug release in the upper GIT. The shift in the $T_{\max }$ to a higher value is typical for the colonic systems (22). But after reaching the colonic environment, drug release from colon-targeted tablet by disintegration of swollen cellulose tablets was progressive. The AUC of core and F6 tablets were 41,238.52 \pm 96.11 and 72,369.24 \pm $153.26 \mathrm{ng}-\mathrm{h} / \mathrm{ml}$, correspondingly. These results indicated that the colon-targeted compression-coated tablets retard the drug appreciably in the upper GIT, but slow drug release in colon was observed. The MRT of FLB core and colonic tablets were 3.43 and $10.61 \mathrm{~h}$, respectively, indicating long resident time for double-compression-coated tablet.

From the statistical analysis of pharmacokinetic parameters, there was a significant difference in the $C_{\max }$ between core and F6 tablets, demonstrating that colon-targeted tablets did not release the FLB in the upper GIT. Comparable kind of results observed in guar gum-based colon-targeted tablets of mebendazole (23). The $T_{\max }$, AUC, and MRT of core tablets were significantly different from F6 double-compressioncoated tablets representing delayed release of FLB specifically to the colon in a slow manner. From the IVIVC results, there was a good correlation between the in vitro and in vivo parameters. In conclusion, the core tablets showed quick drug release that resulted in early $T_{\max }$ and higher $C_{\max }$. But the F6 tablets were able to show negligible drug release in $5 \mathrm{~h}$ lag time and majority of drug released in the colon resulted in delayed $T_{\max }(12 \mathrm{~h})$. From all these perceptions, it was inferred that the double-compression-coated pulsatile tablets using time- and $\mathrm{pH}$-dependent approaches were indicated immaterial FLB release in stomach and small intestine, yet released promisingly in colon.

\section{CONCLUSIONS}

Formulation of pulsatile double-compression-coated tablets proved to be the most successful approach to gain the colon-specific release of FLB with negligible drug release in stomach and small intestine. In the present study, HPMC K10M and Eudragit S100 were investigated as inner and outer compression-coated polymers based on time- as well as $\mathrm{pH}$ dependent approaches. From the in vitro drug release and in vivo pharmacokinetic studies, F6 formulation released a considerable amount of drug in the colon with minimum release in lag period of $5 \mathrm{~h}$ with proved stability of drug in compression coat. All in all, development of pulsatile double-compression-coated tablets using FLB core minitablets is a decent approach for colon-specific drug release.

\section{ACKNOWLEDGMENTS}

The authors acknowledge FDC Limited, Mumbai, India and Matrix laboratories, Hyderabad, India for the gift sample of flurbiprofen, HPMC K100M, and Eudragit S100. The authors also thank Management, Jangaon Institute of Pharmaceutical Sciences and Chaitanya College of Pharmacy Education and Research for providing the facilities.

Conflict of Interest The author declares that he has no competing interests.

\section{REFERENCES}

1. Vemula SK, Veerareddy PR. Fast disintegrating tablets of flurbiprofen: formulation and characterization. Lat Am J Pharm. 2011;30:1135-41.

2. Orlu M, Cevher E, Araman A. Design and evaluation of colonspecific drug delivery system containing flurbiprofen microsponges. Int J Pharm. 2006;318:103-17.

3. Philip AK, Dubey RK, Pathak K. Optimizing delivery of flurbiprofen to the colon using a targeted prodrug approach. J Pharm Pharmacol. 2008;60:607-13.

4. Vemula SK, Veerareddy PR. Different approaches to design and evaluation of colon specific drug delivery systems. Int J Pharm Technol. 2009;1(1):1-35.

5. Hashem FM, Shaker DS, Nasr M, Saad IE, Ragaey R. Guar gum and hydroxypropyl methylcellulose compressed coated tablets for colonic drug delivery: in vitro and in vivo evaluation in healthy human volunteers. Drug Discov Ther. 2011;5:90-5.

6. Veerareddy PR, Vemula SK. Formulation, evaluation and pharmacokinetics of colon targeted pulsatile system of flurbiprofen. J Drug Target. 2012;20:703-14.

7. Chickpetty SM, Baswaraj R, Nanjwade BK. Studies on development of novel combined time and $\mathrm{pH}$ dependent solventless compression coated delivery systems for colonic delivery of diclofenac sodium. Asian J Pharm Clin Res. 2010;3(2):110-3.

8. Maroni A, Curto MDD, Serratoni M. Feasibility, stability and release performance of a time-dependent insulin delivery system intended for oral colon release. Eur J Pharm Biopharm. 2009;72:246-51.

9. Srivastava R, Kumar D, Pathak K. Colonic luminal surface retention of meloxicam microsponges delivered by erosion based colon-targeted matrix tablet. Int J Pharm. 2012;427:153-62.

10. Asghar LF, Chure CB, Chandran S. Colon specific delivery of indomethacin: effect of incorporating $\mathrm{pH}$ sensitive polymers in xanthan gum matrix bases. AAPS PharmSciTech. 2009;10(2):418-29.

11. Wu B, Shun N, Wei X, Wu W. Characterization of 5-fluorouracil release from hydroxypropyl methylcellulose compression-coated tablets. Pharm Dev Technol. 2007;12:203-10.

12. Vemula SK, Veerareddy PR, Devadasu VR. Pharmacokinetics of colon-specific $\mathrm{pH}$ and time-dependent flurbiprofen tablets. Eur J Drug Metab Pharmacokinet. 2014. doi:10.1007/s13318-014-0210-0.

13. Vemula SK, Veerareddy PR, Devadasu VR. Pharmacokinetics of ketorolac tromethamine compression-coated tablets for colon delivery. Drug Del Trans Res. 2014;4:310-9.

14. Vemula SK, Veerareddy PR. Development, evaluation and pharmacokinetics of time-dependent ketorolac tromethamine tablets. Expert Opin Drug Deliv. 2013;10:33-45.

15. Vemula SK, Bontha VK. Colon targeted gaur gm compression coated tablets of flurbiprofen: formulation, development and pharmacokinetics. BioMed Res Int. 2013. doi:10.1155/2013/ 287919. Article ID 287919.

16. Ishida M, Abe K, Hashezime M, Kawamura M. A novel approach to sustained pseudoephedrine release-differentially coated mini-tablets in HPMC capsules. Int J Pharm. 2008;359:46-52.

17. Valluru R, Siddaramaiah T, Pramod M. Influence of natural polymer coating on novel colon targeting drug delivery system. J Mater Sci. 2008;19:2131-6.

18. Talukder RM, Fassihi R. Development and in-vitro evaluation of a colon-specific controlled release drug delivery system. J Pharm Pharmacol. 2008;60:1297-303. 
19. Chaudhary A, Tiwari N, Jain V, Singh R. Microporous bilayer osmotic tablet for colon-specific delivery. Eur J Pharm Biopharm. 2011;78:134-40.

20. Mathews BR. Regulatory aspects of stability testing in Europe. Drug Dev Ind Pharm. 1999;25:831-56.

21. Wu B, Shun N, Wei X, Lu Y, Wu W. Biphasic release of indomethacin from HPMC/pectin/calcium matrix tablet: I. Characterization and mechanistic study. Eur J Pharm Biopharm. 2007;67:707-14.
22. Krishnaiah YSR, Satyanarayana S, Kumar DB, Karthikeyan RS, Bhaskar P. In vivo pharmacokinetics in human volunteers: oral administered guar gum-based colon-targeted 5-fluorouracil tablets. Eur J Pharm Sci. 2003;19:355-62.

23. Krishnaiah YSR, Veerraju P, Dineshkumar A, Satyanarayana V, Karthikeyan RS, Bhaskar P. Pharmacokinetic evaluation of guar gum-based colon-targeted drug delivery systems of mebendazole in healthy volunteers. J Control Release. 2003;88:95-103. 